\title{
Anaerobic Metabolism in Tidal Freshwater Wetlands: I. Plant Removal Effects on Iron Reduction and Methanogenesis
}

\author{
Jason K. Keller • Ariana E. Sutton-Grier • \\ Allyson L. Bullock • J. Patrick Megonigal
}

Received: 30 May 2011 /Revised: 21 February 2012 / Accepted: 3 June 2012

(C) Coastal and Estuarine Research Federation 2012

\begin{abstract}
For energetic reasons, iron reduction suppresses methanogenesis in tidal freshwater wetlands; however, when iron reduction is limited by iron oxide availability, methanogenesis dominates anaerobic carbon mineralization. Plants can mediate this microbial competition by releasing oxygen into the rhizosphere and supplying oxidized iron for iron reducers. We utilized a plant removal experiment in two wetland sites to test the hypothesis that, in the absence of plants, rates of iron reduction would be diminished, allowing methanogenesis to dominate anaerobic metabolism. In both sites, methanogenesis was the primary anaerobic mineralization pathway, with iron reduction dominating only early and late in the growing season in the site with a less organic soil. These patterns were not influenced by the presence of plants, demonstrating that plants were not a key control of microbial metabolism. Instead, we suggest that site conditions, including soil chemistry, and temperature are important controls of the pathways of anaerobic metabolism.
\end{abstract}

Keywords Anaerobic microbial metabolism · Iron reduction - Jug Bay Wetlands Sanctuary, Maryland, USA . Methane $\cdot$ Plant removal $\cdot$ Tidal freshwater wetland

\section{J. K. Keller}

School of Earth and Environmental Sciences,

Chapman University,

Orange, CA 92782, USA

J. K. Keller $(\triangle)$ • A. E. Sutton-Grier • A. L. Bullock •

J. P. Megonigal

Smithsonian Environmental Research Center,

Edgewater, MD 21037, USA

e-mail: jkeller@chapman.edu

\section{Introduction}

Globally, wetland soils store approximately one third of the terrestrial soil carbon (Bridgham et al. 2006) and are responsible for between $20 \%$ and $39 \%$ of global methane $\left(\mathrm{CH}_{4}\right)$ emissions (Denman et al. 2007). These important links between wetland ecosystems and the global carbon cycle are, in large part, a consequence of anaerobic soil conditions resulting from flooded or saturated soils in wetland environments. Under these oxygen-limited conditions, mineralization of organic matter in wetland soils relies on a complex microbial assemblage that ultimately mineralizes organic compounds to carbon dioxide $\left(\mathrm{CO}_{2}\right)$ and/or $\mathrm{CH}_{4}$ (Megonigal et al. 2004).

While the cumulative rates of microbial mineralization are controlled by organic matter quality and climatic variables such as temperature, the ratio of the end products of this anaerobic mineralization (i.e., $\mathrm{CO}_{2}: \mathrm{CH}_{4}$ ) is in large part determined by competition between various microbial processes. It is generally assumed that the outcome of this competition is dependent on the energetic favorability of the terminal electron acceptors (TEAs) used by competing microbes (Megonigal et al. 2004). In order of decreasing energetic yield, and thus decreasing competitiveness, the primary inorganic TEAs used in the absence of oxygen are: $\mathrm{NO}_{3}{ }^{-}$(denitrification), $\mathrm{Mn}(\mathrm{III}, \mathrm{IV})$ (manganese reduction), $\mathrm{Fe}$ (III) (iron reduction), and $\mathrm{SO}_{4}{ }^{2-}$ (sulfate reduction). These processes release $\mathrm{CO}_{2}$ as a respiratory end product, and carbon mineralization in soils dominated by these microbial pathways is characterized by a high $\mathrm{CO}_{2}: \mathrm{CH}_{4}$ ratio. Only after these more energetically favorable TEAs have been consumed is $\mathrm{CH}_{4}$ produced, resulting in a 1:1 ratio of $\mathrm{CO}_{2}: \mathrm{CH}_{4}$ under conditions where $\mathrm{CH}_{4}$ production is the dominant mineralization process (Conrad 1999). It should 
be noted that the aerobic oxidation of $\mathrm{CH}_{4}$ as well as autotrophic respiration also produce $\mathrm{CO}_{2}$, resulting in higher ratios even when $\mathrm{CH}_{4}$ production dominates anaerobic decomposition. This confounds the interpretation of the $\mathrm{CO}_{2}$ : $\mathrm{CH}_{4}$ ratio under field conditions in the presence of plant roots and oxidized soil volumes but does not influence the ratio observed in anaerobic laboratory incubations. $\mathrm{As}^{\mathrm{CH}_{4}}$ has 25 times the global warming potential of $\mathrm{CO}_{2}$ (on a molar basis over the 100 year time frame Forster et al. 2007), understanding the ratio of these two gases produced during anaerobic carbon mineralization in wetlands has important implications for understanding the role that wetlands will play in the context of global climate change.

Tidal freshwater wetlands are unique in their carbon biogeochemistry as a result of regular tidal inundation, which ensures that the depth of $\mathrm{O}_{2}$ penetration is relatively stable across seasons and that below this zone of atmospheric $\mathrm{O}_{2}$ influence organic matter mineralization generally proceeds anaerobically (Megonigal and Neubauer 2009). In comparison to tidal saline or brackish systems where $\mathrm{SO}_{4}{ }^{2-}$ is continuously resupplied by tide water, tidal freshwater systems are generally thought to have higher rates of $\mathrm{CH}_{4}$ production because methanogens are released from competition with sulfate reducers (Bartlett et al. 1987; Bridgham et al. 2006; Kelley et al. 1990). However, in recent years, there has been a growing appreciation that $\mathrm{CH}_{4}$ production in tidal freshwater systems can also be competitively suppressed by iron reduction. Indeed, microbial iron reduction was first demonstrated in freshwater sediments (Lovley and Phillips 1986a) and has been shown to be a competitively superior anaerobic carbon mineralization pathway in wetland ecosystems (Roden 2003; Roden and Wetzel 1996; 2003). For these reasons, tidal freshwater wetlands are a useful model ecosystem for studying anaerobic metabolism when the goal is to separate the influence of hydrologic variation from other sources of variation such as plant activity.

Iron reduction in freshwater wetlands is frequently limited by the availability of labile oxidized iron to serve as a TEA (Roden and Wetzel 2002). In flooded soils where atmospheric $\mathrm{O}_{2}$ availability is limited, the re-oxidation of iron has been linked to $\mathrm{O}_{2}$ transport by plants to rhizosphere soils (e.g., Giblin and Howarth 1984; Neubauer et al. 2002). There is a large body of evidence suggesting that labile, poorly crystalline iron oxides are enriched in the rhizosphere compared with root-free soils (e.g., Kostka and Luther 1995; Weiss et al. 2004), and rates of iron reduction are frequently observed to be higher in vegetated soils (e.g., Roden and Wetzel 1996; Weiss et al. 2004).

Taken together, these results suggest that plant activity (i.e., $\mathrm{O}_{2}$ transport to the rhizosphere) may serve as a key mediator of the competition between iron reducers and methanogens in freshwater wetlands by regulating iron availability in these systems. Using potted plants, SuttonGrier and Megonigal (2011) demonstrated that more productive wetland plants transported greater amounts of $\mathrm{O}_{2}$ belowground, creating larger pools of oxidized iron, thereby stimulating iron reduction while concomitantly suppressing $\mathrm{CH}_{4}$ production. Neubauer et al. (2005) hypothesized a similar mechanism to explain seasonal patterns in $\mathrm{CH}_{4}$ production in a tidal freshwater wetland. In this project, we used an ecosystem-level plant removal experiment to test the hypothesis that, in the absence of plants, rates of iron reduction will be diminished as a result of reduced $\mathrm{O}_{2}$ inputs to the rhizosphere, thus allowing the competitively inferior process of methanogenesis to dominate anaerobic carbon mineralization. This ecosystem-scale test of this hypothesis has important implications for understanding how plantmicrobe interactions regulate carbon dynamics in a tidal freshwater ecosystem specifically and in freshwater wetlands generally.

\section{Materials and Methods}

\section{Site Description}

This project took place at the Jug Bay Wetlands Sanctuary located along the freshwater portion of the Patuxent River in Lothian, Maryland. Patuxent River salinity measured monthly near Jug Bay (EPA monitoring station TF1.4) had an average of $0.03 \mathrm{~g}$ salt per kg water (range, $0-0.85 \mathrm{~g} \mathrm{~kg}^{-1}$ ) from January 2007 to December 2008, the timeframe of this study (William Romano, Maryland Department of Natural Resources, personal communication). Although these are freshwater systems, they are also tidal, usually receiving two high tides and two low tides each day. Tidal freshwater systems were selected for this project to ensure that soils were frequently flooded and that the water table did not drop below the rooting zone during seasonally dry periods.

Two wetland sites within the Jug Bay Wetlands Sanctuary were designated for this project. Both were selected based on a dominant coverage by Typha spp. (common cattail), a wetland genus that has been shown to form oxidized iron plaques in the rhizosphere (Taylor et al. 1984). Other species present included Peltandra virginica (arrow arum) and Polygonum arifolium (Halberdleaf tear thumb). Both sites typically experienced two high and low tides each day. The first site ("Organic Site"; N $38^{\circ} 46^{\prime} 51.30$, W $76^{\circ} 42^{\prime} 43.56$ ) was characterized by a highly organic soil (percent organic matter $=58.1 \% \pm 1.7 \%$, mean \pm 1 SE, $n=6$ ), and the second site ("Mineral Site"; N 38 46'51.84, W 76 $42^{\prime} 48.16$ ) had a more mineral-rich soil (percent organic matter $=29.7 \% \pm 1.2 \%, n=6$ ). Percent organic matter was determined by loss on ignition at $550{ }^{\circ} \mathrm{C}$ using soils collected in June of 2008 from both sites. These sites were located 
$\sim 110 \mathrm{~m}$ from each other with the Organic Site further $(\sim 140 \mathrm{~m})$ from the main river channel than the Mineral Site.

While we focus on relative soil organic matter content in identifying these sites, we acknowledge that this nomenclature is somewhat arbitrary given that a number of other relevant, but unmeasured, environmental factors also likely varied between these locations. These include relative elevation and hydroperiod, porewater flushing rates, sedimentation dynamics, and perhaps rooting depth profiles with more established organic sites at Jug Bay having deeper rooting depths than more recently established mineral locations (Aat Barendregt, personal communication). While relative organic matter content is likely to be an important environmental control over microbial processes and does vary dramatically between sites, our use of this soil property to identify these sites is not intended to suggest that this is the only, or most important, property that defines these sites ecologically. It is also possible that iron chemistry and availability differs between these locations. While we do not have detailed measurements of iron chemistry, total extractable iron determined on air-dried soils using a weakly acidic oxalate extract (Phillips and Lovley 1987) in conjunction with a total iron buffer ( $1 \%$ hydroxylamine hydrocholoride in ferrozine) was higher at the Organic Site $(140.7 \pm 6.8 \mu \mathrm{mol}$ $\mathrm{Fe} \mathrm{gdw}^{-1}$, mean $\pm 1 \mathrm{SE}, n=6$ ) compared with the Mineral Site $\left(102.3 \pm 11.0 \mu \mathrm{mol} \mathrm{Fe} \mathrm{gdw}^{-1}, n=6\right)$ in April of 2008. In June of 2008, however, there were smaller differences between the sites with total iron contents of $162 \pm 14.4 \mathrm{mmol} \mathrm{Fe} \mathrm{gdw}^{-1}$ at the Organic Site and $145.5 \pm 33.2 \mu \mathrm{mol} \mathrm{Fe} \mathrm{gdw}^{-1}$ at the Mineral Site.

\section{Plant Removal Treatment}

A meter-scale aboveground biomass removal treatment was initiated to explore the impact of rhizospheric $\mathrm{O}_{2}$ loss by wetland plants on the competition between iron reducers and methanogens in these two tidal freshwater wetlands. At the Organic Site, $121.5 \times 1.5 \mathrm{~m}$ plots were lined with aluminum flashing to a depth of $30 \mathrm{~cm}$. This depth includes the majority of the root depth distribution, with most roots generally limited to the upper $20 \mathrm{~cm}$ based on a survey of root distributions at Jug Bay Wetlands Sanctuary (Aat Barendregt, personal communication). Plots were separated by $1 \mathrm{~m}$, and temporary boardwalks were installed between the plots to minimize disturbance. In November 2006, all aboveground biomass in each plot was clipped below the soil surface, transported to the laboratory at the Smithsonian Environmental Research Center and allowed to air dry for 1 week before being weighed. Three stems of Typha from each plot were weighed and then dried at $60{ }^{\circ} \mathrm{C}$ for $48 \mathrm{~h}$ to correct air-dried biomass to oven-dried biomass. Dried biomass was returned to the field and evenly distributed over the plots. New biomass was allowed to regrow through the end of June 2007.
Beginning in July 2007, all aboveground vegetation was cut below the soil surface in six of the plots ("No Plant" treatment) while the vegetation was left undisturbed in the remaining six plots ("Plant" treatment). Initial aboveground biomass (methods described above) was $630 \pm 54 \mathrm{~g}$ ovendried biomass $\mathrm{m}^{-2}$ in the Plant plots and $689 \pm 56 \mathrm{~g}$ ovendried biomass $\mathrm{m}^{-2}$ in the No Plant plots (mean $\pm 1 \mathrm{SE} ; n=6$ ). There were no initial differences in aboveground biomass between these treatments ( $p=0.47$; independent $t$ test). These estimates are on the low end of reported aboveground net primary productivity for tidal freshwater marshes which ranges from $800-2,000 \mathrm{~g}$ biomass $\mathrm{m}^{-2}$ year $^{-1}$ (Whigham 2009); however, we point out that our biomass estimates were collected in November, well after peak standing biomass had occurred and were not corrected for biomass mortality and turnover. Newly sprouting vegetation in the No Plant plots was cut approximately every 2 weeks through the end of October 2007 and during the growing season (April-October) of 2008. To minimize differences in light dynamics and soil temperatures, the No Plant plots were shaded with window screen held in place approximately $0.5 \mathrm{~m}$ above the soil surface. In 2007, a single layer of shade screen was used, but in 2008, a second layer of shade screen was added to further decrease light reaching the soil surface. Beginning in August of 2007, daily soil temperatures (10-cm depth) were calculated from hourly temperatures recorded in two No Plant and two Plant plots using Hobo Tidbit data loggers (Onset Computer Corporation, Bourne, MA, USA). Despite the use of shade screen, daily average temperatures in the No Plant plots were $0.47 \pm 0.03^{\circ}$ $\mathrm{C}$ (mean $\pm 1 \mathrm{SE})$ warmer than Plant plots, and this difference increased to $0.63 \pm 0.03{ }^{\circ} \mathrm{C}$ warmer when measured over the growing season (April-October). No Plant plots also developed a thick layer of algal biomass on the soil surface, which was removed during each vegetation clipping event.

At the Mineral Site, $120.5 \times 2.0 \mathrm{~m}$ plots were lined with aluminum flashing to a depth of $30 \mathrm{~cm}$ beginning in December of 2007. Based on experience with the Organic Site, smaller plot dimensions were used at the Mineral Site to minimize disturbance and to facilitate the collection of soil cores for the rate measurements described below. Plots were separated by $2 \mathrm{~m}$, and boardwalks were installed to minimize disturbance. Beginning in July 2008, all aboveground vegetation was cut in half of the plots ("No Plant" treatment) while the vegetation was left undisturbed in the remaining six plots ("Plant" treatment). In contrast to the Organic Site, vegetation in the Plant plots was not initially clipped at this site. Newly emerging vegetation was cut approximately every 2 weeks through the end of October in the No Plant plots. Two layers of shade screen were used to decrease light reaching the soil surface in the No Plant plots. Because two adjacent plots (one from each treatment) were outliers in the carbon mineralization measurements described below, they 
were excluded from all analyses, and there were effectively five replicate plots from each treatment at the Mineral Site.

The primary goal of these plant removals was to decrease the radial $\mathrm{O}_{2}$ loss in the rhizosphere in order to limit rates of iron oxidation in this soil volume. We measured belowground productivity using root ingrowth cores as a proxy for the volume of soil that could be influenced by $\mathrm{O}_{2}$ loss through the root volume. Soil cores to a depth of $30 \mathrm{~cm}$ were initially collected using an aluminum core $(5.08 \mathrm{~cm}$ i.d.). The remaining holes were lined with root ingrowth bags made from $1 \mathrm{~cm}$-mesh nylon bags which were subsequently filled with root-free soil collected from the surface of an adjacent area at the Jug Bay Wetlands Sanctuary. There were three ingrowth bags placed in each plot at the Organic Site in July 2007, shortly after the plant removal treatment was initiated. In November 2007, the root ingrowth bags were collected, and all live belowground biomass (including roots and rhizomes) was removed by hand, washed, and allowed to dry to a constant mass at $60{ }^{\circ} \mathrm{C}$. Ten additional ingrowth core bags were placed outside of the experimental plots over the same time period. Root ingrowth data were not intended to reflect accurate measurements of seasonal belowground productivity; rather, they were utilized to demonstrate an effective decrease in belowground activity in response to our aboveground vegetation treatment. Given that similar protocols were used at both sites, we assume that our vegetation removal at the Mineral Site was also effective in this regard.

\section{Porewater Measurements}

Soil porewater was collected approximately monthly during the growing season (April-October) in both the Organic and Mineral Sites. At the Organic Site, porewater collection began in May of 2007 and included two sampling dates prior to the initiation of the vegetation removal treatments. At the Mineral Site, porewater collection began in May of 2008 and included three sampling dates prior to the initiation of the vegetation removal treatments. All porewater was collected using "sipper" wells (Marsh et al. 2005; Keller et al. 2009). These wells were installed at depths of 10, 30, and $50 \mathrm{~cm}$ below the soil surface (three wells per depth) in each plot prior to the initiation of the plant removal treatment. All wells were constructed from Teflon tubing $(9 \mathrm{~mm}$ o.d. $\times$ $6 \mathrm{~mm}$ i.d.) with holes in each well extending $2 \mathrm{~cm}$ above and below each sampling depth. The bottoms of the wells were sealed with silicone caulk, and vinyl tubing $(0.64 \mathrm{~cm}$ o.d. $\times 0.32 \mathrm{~cm}$ i.d.) extended approximately $1 \mathrm{~m}$ from the top of each well to a three-way stopcock used for sampling.

On each sampling date, two $30-\mathrm{mL}$ syringes of porewater were collected from each sampling depth in each experimental plot. Initially, each well was flushed by collecting and immediately discarding at least $30 \mathrm{~mL}$ of porewater.
Subsequently, a second 30-mL sample was collected from each well, and $10 \mathrm{~mL}$ volumes of this sample were transferred to two $30-\mathrm{mL}$ syringes using three-way stopcocks to minimize exposure to the ambient atmosphere. The remaining two wells were sampled in a similar manner, resulting in two $30-\mathrm{mL}$ syringes containing composites of the samples from the three wells of a given depth in each plot.

The sample in the first syringe was used to measure dissolved $\mathrm{CH}_{4}$ using a headspace equilibration technique (Keller et al. 2009). Fifteen milliliters of porewater from each syringe was discarded. Dissolved $\mathrm{CH}_{4}$ was stripped from the remaining $15 \mathrm{~mL}$ of porewater by introducing a $15 \mathrm{~mL}$ headspace of ambient atmosphere and shaking vigorously for $30 \mathrm{~s}$ to strip trapped $\mathrm{CH}_{4}$. The remaining porewater was expelled from the syringe, and the $15 \mathrm{~mL}$ of headspace (containing the stripped $\mathrm{CH}_{4}$ ) was analyzed using a Shimadzu GC-15A gas chromatograph (Shimadzu Corporation, Kyoto, Japan) equipped with a flame ionization detector. $\mathrm{CH}_{4}$ samples were analyzed on the same day of sample collection.

Porewater in the second syringe was used to measure dissolved sulfide by adding $3 \mathrm{~mL}$ of unfiltered porewater to $3 \mathrm{~mL}$ of alkaline antioxidant $(2 \mathrm{~mol} / \mathrm{L} \mathrm{NaOH}, 0.2 \mathrm{~mol} / \mathrm{L}$ $\mathrm{Na}_{2} \mathrm{H}_{2}$ ethylenediaminetetraacetic acid, $0.2 \mathrm{~mol} / \mathrm{L}$ ascorbic acid) prepared in deoxygenated water prior to sampling. Sulfide concentrations were measured using an ionselective electrode (Eaton et al. 1995). Sulfide concentrations at these freshwater sites were generally below $10 \mu \mathrm{mol} / \mathrm{L}$ and are not reported in more detail here. Following sulfide measurements, the remaining porewater in the second syringe was filtered through a preleached Millipore nitrocellulose syringe filter $(0.45 \mu \mathrm{m}$ poresize $)$ into a plastic scintillation vial. A subsample of this filtered sample was immediately collected and added to ferrozine reagent $(0.1 \%$ ferrozine in HEPES buffer, $\mathrm{pH}=7.0$ ) to measure dissolved $\mathrm{Fe}(\mathrm{II})$ concentrations (Lovley and Phillips 1986b).

\section{Net Ecosystem Respiration}

At the Organic Site, we measured rates of net ecosystem respiration (NER, as $\mathrm{CO}_{2}$ and $\mathrm{CH}_{4}$ flux) using dark static chambers. NER measurements were made approximately monthly from July-October in 2007 and included one sampling date before the plant removal treatment was initiated. A $50 \times 50 \mathrm{~cm}$ aluminum base was installed to a depth of $30 \mathrm{~cm}$ in five replicate plots for each treatment. Static chambers were constructed from $2.5 \times 2.5 \mathrm{~cm}$ aluminum angle stock and covered with construction plastic to create an airtight chamber. The construction plastic sides were covered with panels of foam insulation board that reflected solar radiation in order to minimize changes in the chamber air temperatures. The bottom of each chamber was lined with high-density closed-cell foam and clipped to the bases 
installed in the field on each sampling date. A plexiglass lid, also lined with high-density closed-cell foam, was clipped to the top of each chamber immediately prior to sampling. Headspace samples were collected with $30-\mathrm{mL}$ syringes upon capping the chambers and again every $30 \mathrm{~min}$ for a period of $2 \mathrm{~h}$. Headspace samples were analyzed for $\mathrm{CH}_{4}$ using a Shimadzu GC-15A gas chromatograph and for $\mathrm{CO}_{2}$ using a LiCor LI-7000 (Lincoln, NE, USA). Rates of both $\mathrm{CO}_{2}$ and $\mathrm{CH}_{4}$ flux were generally linear $\left(r^{2}>0.90\right)$, and nonlinear values were excluded from subsequent analyses (of 50 NER measurements, three $\mathrm{CH}_{4}$ fluxes, and two $\mathrm{CO}_{2}$ fluxes were excluded for non-linearity). NER measurements were typically made during periods of low tide; however, tidal conditions changed over the course of these measurements, and periodic soil flooding did occur. We did not calculate changes in dissolved $\mathrm{CO}_{2}$ or $\mathrm{CH}_{4}$ associated with these tidal changes which could have influenced net flux measurements; however, the general linear response of NER suggests that these impacts were minimal.

We also present the non-methanogenic $\mathrm{CO}_{2}$ flux measured in the NER chambers. For this value, we assumed that $\mathrm{CH}_{4}$ was produced solely by soil microorganisms while $\mathrm{CO}_{2}$ was a result of the combination of heterotrophic respiration, including methanotrophy and other aerobic processes, as well as autotrophic plant and algal respiration. Nonmethanogenic $\mathrm{CO}_{2}$ flux was estimated by subtracting the $\mathrm{CO}_{2}$ produced by methanogens assuming a 1:1 ratio of $\mathrm{CO}_{2}$ : $\mathrm{CH}_{4}$ production (Conrad 1999). Seasonal fluxes of $\mathrm{CH}_{4}$ were generated by linearly extrapolating daily rates between sampling dates and then summing these rates over the 2007 growing season.

\section{Rates of Carbon Mineralization}

To measure rates of anaerobic carbon mineralization, soil cores were collected from each plot. At the Organic Site, cores were collected six times over the course of this experiment, including one collection prior to the initiation of the plant removal treatment. At the Mineral Site, cores were collected five times over the 2008 growing season, including three collections prior to the initiation of the plant removal treatment. All soil samples were collected using $6.3-\mathrm{cm}$ diameter stainless steel cores which were inserted to a depth of $\sim 20 \mathrm{~cm}$ being careful to minimize soil compaction. The tops of the cores were sealed with a stopper to create an airtight seal, and the core (with soil) was removed from each plot and immediately capped on the bottom to minimize oxygen exposure. Within $24 \mathrm{~h}$ of collection, the soil cores were brought into an anaerobic chamber (Coy Laboratory Products, Inc., Grasslake, MI) with a headspace of $>95 \% \mathrm{~N}_{2}$ and $<5 \% \mathrm{H}_{2}\left(\mathrm{H}_{2}\right.$ is used to remove $\mathrm{O}_{2}$ in the presence of a palladium catalyst). We used the $5-10 \mathrm{~cm}$ depth increment from each core for further analyses on the assumption that the water table rarely falls below $5 \mathrm{~cm}$ and the primary source of $\mathrm{O}_{2}$ to regenerate iron oxides at this depth is from roots rather than the atmosphere. Large roots and litter were removed from the bulk soil in this depth increment using forceps. Approximately $15 \mathrm{~mL}$ of root-free soil was added to a $60-\mathrm{mL}$ serum bottle along with $5 \mathrm{~mL}$ of degassed, deionized water to create a slurry. A total of four slurries were created for each plot on each sampling date. All serum bottles were capped with gray butyl septa, removed from the anaerobic chamber and flushed with $\mathrm{N}_{2}$ for 30 min to remove as much $\mathrm{H}_{2}$ as possible and ensure anaerobic conditions. Despite differences in soil temperatures in the field when the samples were collected, soils were incubated in the dark at $20{ }^{\circ} \mathrm{C}$ on all sampling dates. This approach allowed for comparisons of microbial rates based upon constraints imposed by Fe(III) pool size, carbon availability, and other factors which likely varied seasonally in the field, but without the confounding effect of incubation temperature.

The first two slurries from each plot were used as duplicates to measure rates of potential $\mathrm{CO}_{2}$ and $\mathrm{CH}_{4}$ production by measuring the accumulation of these gases in the headspace over a period of 3-4 days. Subsamples of the headspace volume were removed and analyzed for $\mathrm{CH}_{4}$ on a Shimadzu GC-15A gas chromatograph and additional subsamples were analyzed for $\mathrm{CO}_{2}$ using a LiCor LI-7000 modified to accept sub-milliliter injections. Rates measured on duplicate bottles were averaged to determine plotspecific rates for $\mathrm{CO}_{2}$ and $\mathrm{CH}_{4}$ production (i.e., plots were the true replicates for statistical analysis). Rates of $\mathrm{CO}_{2}$ and $\mathrm{CH}_{4}$ production were generally linear $\left(r^{2}>0.90\right)$ and nonlinear samples ( 5 out of $61 \mathrm{CH}_{4}$ production samples from the Organic Site) were excluded from subsequent analyses. Following the final headspace analysis, soils were dried to a constant mass at $60{ }^{\circ} \mathrm{C}$ to allow rates of $\mathrm{CO}_{2}$ and $\mathrm{CH}_{4}$ production to be expressed on a per gram dry weight basis.

The remaining two slurries were used as duplicates to measure rates of iron reduction as the accumulation of $\mathrm{Fe}$ (II) measured in a weakly acidic oxalate extract (Phillips and Lovley 1987). Prior to sealing these bottles and then daily over the course of the incubations, the serum bottles were opened in the anaerobic chamber, and a small subsample of soil was added to a $15-\mathrm{mL}$ centrifuge tube along with $10 \mathrm{~mL}$ of extraction solution. We utilized a $0.2 \mathrm{M}$ ammonium oxalate and $0.2 \mathrm{M}$ oxalic acid extraction solution which was degassed prior to being added to the soils. Soils were extracted in the dark by shaking at $250 \mathrm{rpm}$ for $4 \mathrm{~h}$. Following this extraction, soils were centrifuged for $10 \mathrm{~min}$ at $3,400 \mathrm{rpm}$, and ferrous iron (Fe(II)) was quantified in the resulting supernatant using the ferrozine method (Lovley and Phillips 1986b). The remaining supernatant was carefully decanted, and the soil was dried to a constant mass at $60{ }^{\circ} \mathrm{C}$ to express rates of iron reduction on a per gram dry 
weight basis. Rates of duplicate bottles were averaged to generate a plot-specific rate of iron reduction. In the majority of cases, this method did not result in linear $\left(r^{2}>0.90\right)$ rates of iron accumulation. This was most dramatic in the Organic Site where we did not observe Fe(II) accumulation on any sampling date. It is unclear whether this was due to methodological issues (e.g., a lack of sensitivity with this extraction protocol) or if this was a true reflection of microbial processes taking place in these soils. Interestingly, we were able to detect iron reduction in the Mineral Site early and late in the 2008 growing season when the ratio of $\mathrm{CO}_{2}$ : $\mathrm{CH}_{4}$ production in these soils was quite high suggesting a non-methanogenic mineralization pathway dominated these soils (see "Discussion" for more details on this pattern).

\section{Statistical Analysis}

Effects of plant removal on porewater constituents, ecosystem respiration and rates of microbial processes were analyzed in a repeated measures framework with plant treatment as a fixed factor. In all cases, we analyzed both pre-treatment and post-treatment data separately. In cases where a single pre-treatment sampling date was available (e.g., NER measurements at the Organic Site), pre-treatment data were analyzed using independent sample $t$ tests. All statistical analyses were performed using SPSS (2006).

\section{Results}

\section{Changes in Rhizosphere Volume}

We used ingrowth bags to develop an index of the relative rhizosphere volume in our experimental treatments. At the Organic Site, plant removal decreased belowground production by nearly seven-fold from $0.69 \pm 0.12 \mathrm{~g}$ dry belowground biomass per ingrowth bag in the Plant plots to $0.10 \pm 0.03 \mathrm{~g}$ dry belowground biomass per ingrowth bag in the No Plant plots (mean $\pm 1 \mathrm{SE} ; n=6$ ). Ingrowth bags located outside of the experimental plots over the same period suggest that belowground production in our experimental plots was somewhat reduced compared with natural conditions $(1.04 \pm 0.28 \mathrm{~g}$ dry belowground biomass per ingrowth bag; mean \pm 1 S.E.; $n=10$ ), possibly as a result of clipping the plants prior to initiating the experiment or as a result of lining the plots with aluminum flashing.

\section{Porewater Chemistry}

Prior to the initiation of the plant removal treatments at the Organic site in July of 2007 and at the Mineral site in July 2008 , there were no significant differences in concentrations of dissolved $\mathrm{Fe}$ (II) at either site ( $p>0.48$, Fig. 1). Once the vegetation was removed, this pattern continued. There was a slight trend towards higher $\mathrm{Fe}(\mathrm{II})$ concentrations in the shallow depths of the Plant treatments, but this was not significant at any depth in either site $(p>0.52$, Fig. 1). Dissolved $\mathrm{CH}_{4}$ concentrations were similar among all plots at all depths prior to the treatments ( $p>0.21$, Fig. 2$)$ but quickly increased in the No Plant plots following vegetation removal. This pattern was significant at all depths in the Organic Site $(p<0.001)$, but only significant at the $30 \mathrm{~cm}$ depth in the Mineral Site ( $p=0.04$, Fig. 2). The lack of a significant increase in porewater $\mathrm{CH}_{4}$ concentrations at the $10 \mathrm{~cm}$ depth in the Mineral Site ( $p=0.33$, Fig. 2 ) could be a result of low replication $(n=2)$ on the final sampling date when a number of $10 \mathrm{~cm}$ sampling lines were not functional.

\section{Net Ecosystem Respiration}

Based on the dark chamber measurements in the field, there were no differences in $\mathrm{CO}_{2}$ flux or $\mathrm{CH}_{4}$ flux from the Organic Site prior to the initiation of the plant removal treatment ( $p>0.49$, Fig. 3). Once plants were removed, net $\mathrm{CO}_{2}$ flux quickly declined in the No Plant treatment relative to the Plant treatment over the course of the growing season ( $p=0.002$, Fig. 3). The magnitude of this difference decreased as plants senesced at the end of the growing season (Date $\times$ Plant Treatment interaction, $p=0.001$, Fig. 3). Net $\mathrm{CH}_{4}$ flux was lower than net $\mathrm{CO}_{2}$ flux on all sampling dates and did not differ between Plant and No Plant treatments ( $p=0.50$; Fig. 3), even though $\mathrm{CH}_{4}$ fluxes were generally higher from the No Plant plots on most sampling dates. After correcting for the $\mathrm{CO}_{2}$ released by methanogenic activities, rates of non-methanogenic ecosystem $\mathrm{CO}_{2}$ flux (including all non-methanogenic microbial respiration and autotrophic respiration) were higher in the Plant treatments ( $p=0.018$; Fig. 3). Similar to net $\mathrm{CO}_{2}$ flux measurements, the magnitude of this difference decreased as plants senesced at the end of the growing season (Date $\times$ Plant Treatment interaction, $p=0.026$, Fig. 3).

\section{Carbon Mineralization}

At the Organic Site, rates of potential $\mathrm{CO}_{2}$ and $\mathrm{CH}_{4}$ production from anaerobic slurries did not differ between plots prior to the start of the plant removal treatment $(p>0.69)$, and there was no significant effect of plant removal on potential $\mathrm{CO}_{2}$ or $\mathrm{CH}_{4}$ production rates ( $p>0.11$, Fig. 4). By the end of the 2008 growing season, rates of both $\mathrm{CO}_{2}$ and $\mathrm{CH}_{4}$ production were higher in the Plant plots as reflected by the significant Date $\times$ Plant Treatment interactions for $\mathrm{CH}_{4}$ production $(p=0.009)$. This interaction was not significant for $\mathrm{CO}_{2}$ production $(p=0.13)$, but rates of $\mathrm{CO}_{2}$ production were more than doubled in soil from the Plant plots. Across all sampling dates at the Organic Site, 


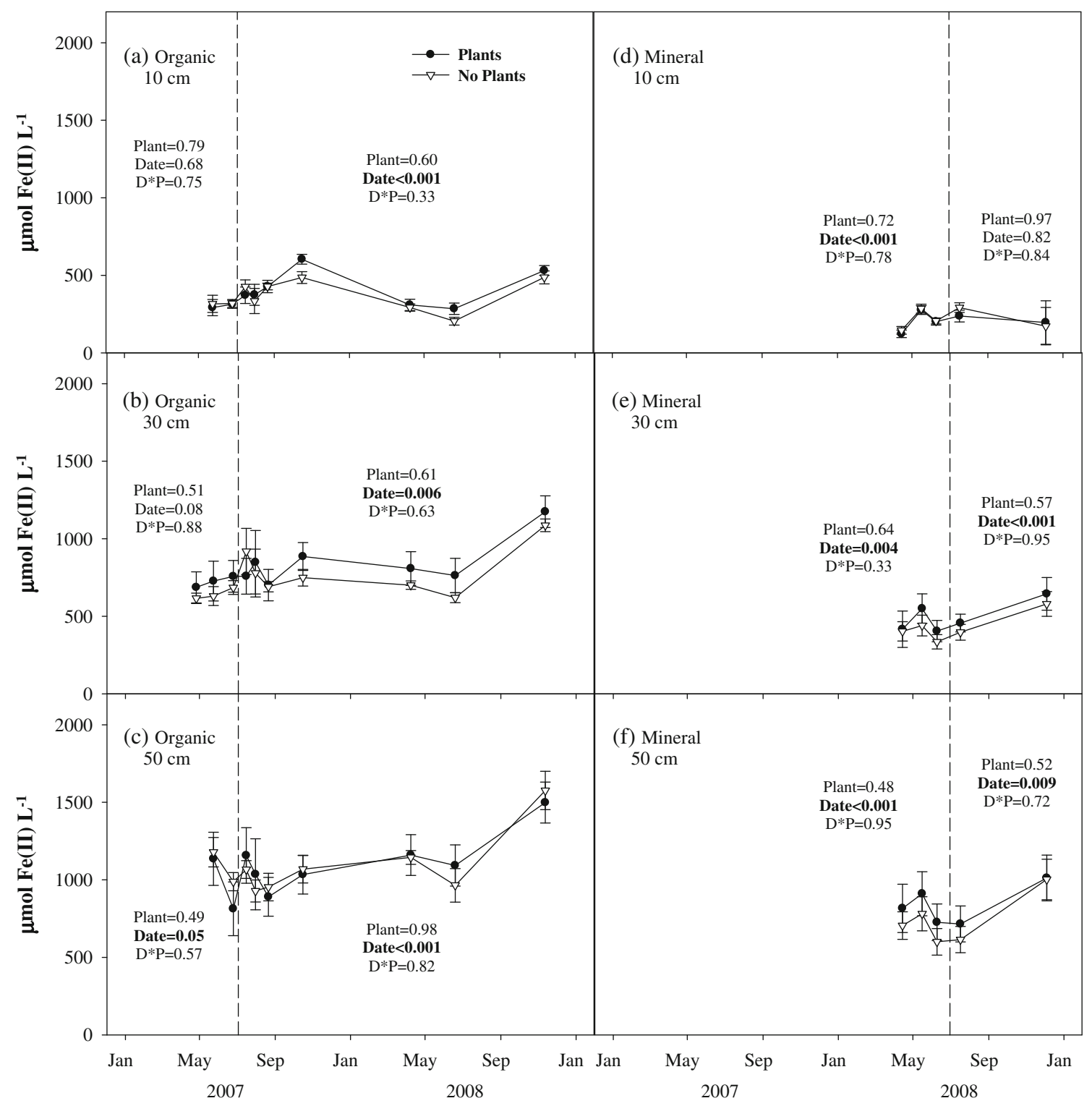

Fig. 1 Effects of plant removal on porewater Fe(II) concentrations in tidal freshwater wetlands with organic $(\mathbf{a}-\mathbf{c})$ and mineral $(\mathbf{d}-\mathbf{f})$ soils. Samples were collected using porewater 'sippers' at depths of 10, 30, and $50 \mathrm{~cm}$ below the soil surface. Values are means $\pm 1 \mathrm{SE}$. The dashed vertical lines indicate the initiation of the plant removal treatment in

the ratio of $\mathrm{CO}_{2}: \mathrm{CH}_{4}$ was close to the $1: 1$ ratio predicted for a methanogenic system, ranging from 0.79 to 1.40 in the Plant plots and 0.84 to 1.13 in the No Plant plots. There was no significant effect of plant removal on $\mathrm{CO}_{2}: \mathrm{CH}_{4}$ at the Organic Site ( $p=0.13$, Fig. 4).

At the Mineral Site, potential $\mathrm{CO}_{2}$ and $\mathrm{CH}_{4}$ production were generally lower than the Organic Site and did not differ between plots prior to the initiation of the plant removal experiment ( $p>0.56$, Fig. 4). There were no significant effects of plant removal on either $\mathrm{CO}_{2}$ or $\mathrm{CH}_{4}$ production ( $p=0.85$ and 0.28 , respectively); however, rates of potential $\mathrm{CH}_{4}$ production showed a distinctive mid-season peak both sites. Results of repeated measures ANOVAs run on pre- and post-treatment data include a fixed effect of the plant treatment ("Plant"), a repeated effect ("Date") and their interaction ("D $\times \mathrm{P}$ "). Significant effects are bolded

(Fig. 4). The lower rates of $\mathrm{CH}_{4}$ production at the start and end of the season resulted in a dramatic seasonal trend in $\mathrm{CO}_{2}: \mathrm{CH}_{4}$ ratio. On the April 2008 sampling date, $\mathrm{CO}_{2}: \mathrm{CH}_{4}$ was above $50: 1$, but quickly dropped to close to $1: 1$ prior to the initiation of the plant removal treatment. This ratio stayed low in both Plant and No Plant plots following the start of the experimental treatments, but increased to 19:1 and 9:1 in the Plant and No Plant plots by December of 2008 (Fig. 4). There was no significant effect of plant removal on $\mathrm{CO}_{2}: \mathrm{CH}_{4}$ ratio $(p=0.39)$ at the Mineral Site.

While quite variable, measured rates of iron reduction at the Mineral Site generally mirrored the seasonal pattern 


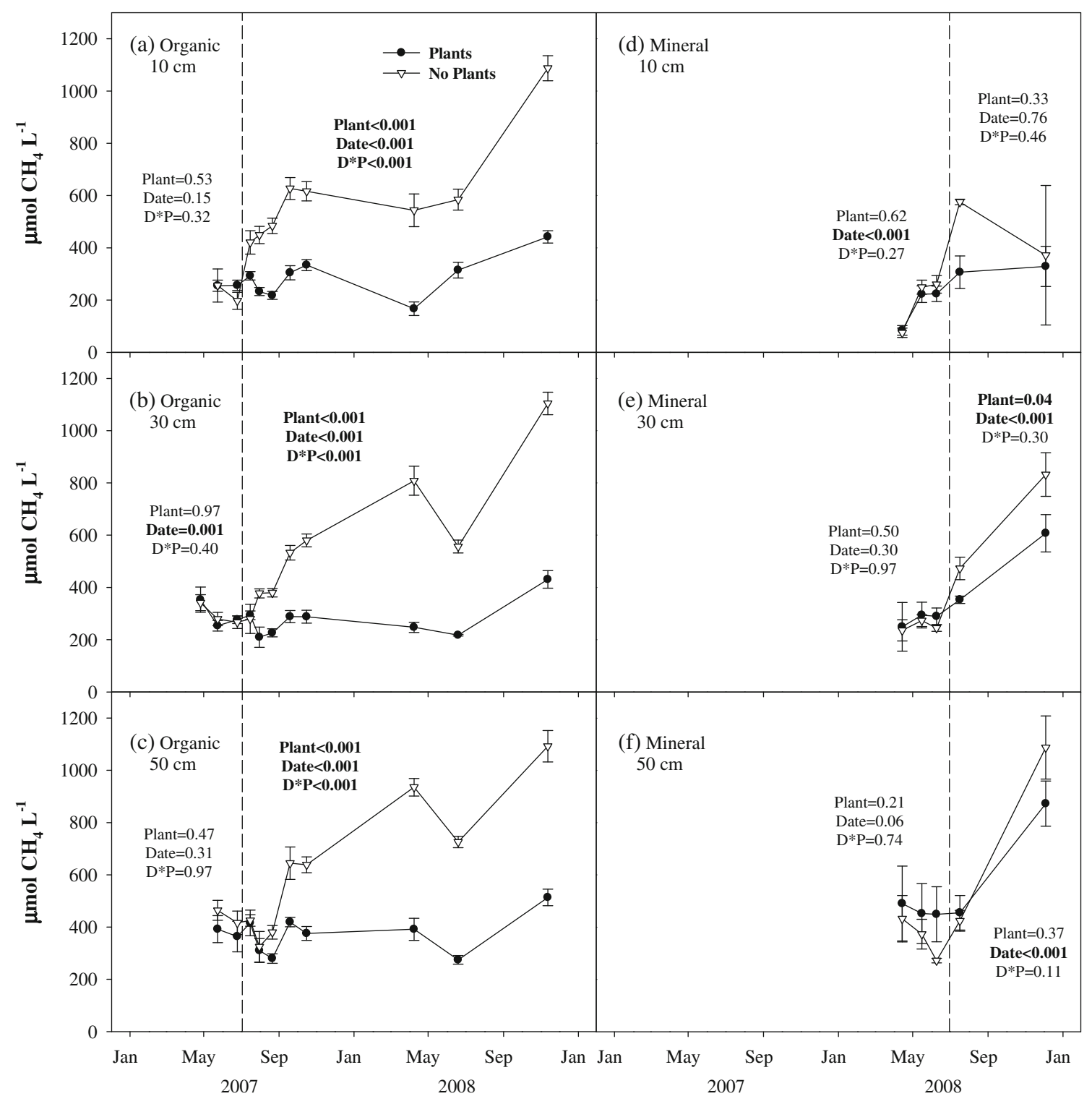

Fig. 2 Effects of plant removal on porewater $\mathrm{CH}_{4}$ concentrations in tidal freshwater wetlands with organic (a-c) and mineral (d-f) soils. Details follow Fig. 1

observed in the $\mathrm{CO}_{2}: \mathrm{CH}_{4}$ ratio (Fig. 5). Iron reduction began high, dropped to close to zero in all plots around the initiation of the plant removal treatment and then began to increase by the final sampling date in December, especially in the Plant treatment (Fig. 5). There were no differences in rates of iron reduction prior to beginning the plant removal treatment $(p=0.50)$ and plant removal did not significantly decrease rates of iron reduction $(p=0.12)$ even though measured rates were higher in the Plant treatment on the final sampling date (Fig. 5). The initial concentrations of extractable $\mathrm{Fe}(\mathrm{II})$ was inversely related to rates of iron reduction and peaked midseason (Fig. 5). There was no effect of plant removal on this pattern $(p=0.47)$, although it appears that this value may have been lower on the final sampling date in soils from the Plant plots given the significant Date $\times$ Plant Treatment interaction $(p=0.05$, Fig. 5). The seasonal pattern of iron reduction generally followed water temperatures in the Patuxent River (Fig. 5).

\section{Discussion}

In contrast to our initial hypothesis, there was little evidence that plant-mediated $\mathrm{O}_{2}$ transport to the rhizosphere was a fundamental control over the competition between iron reducers and methanogens in these tidal freshwater wetland sites. This finding is somewhat surprising given that there were high concentrations of dissolved $\mathrm{Fe}(\mathrm{II})$ in the porewater of both sites (Fig. 1), suggesting that there was ample iron to be (re)oxidized in the plant rhizosphere. The root 


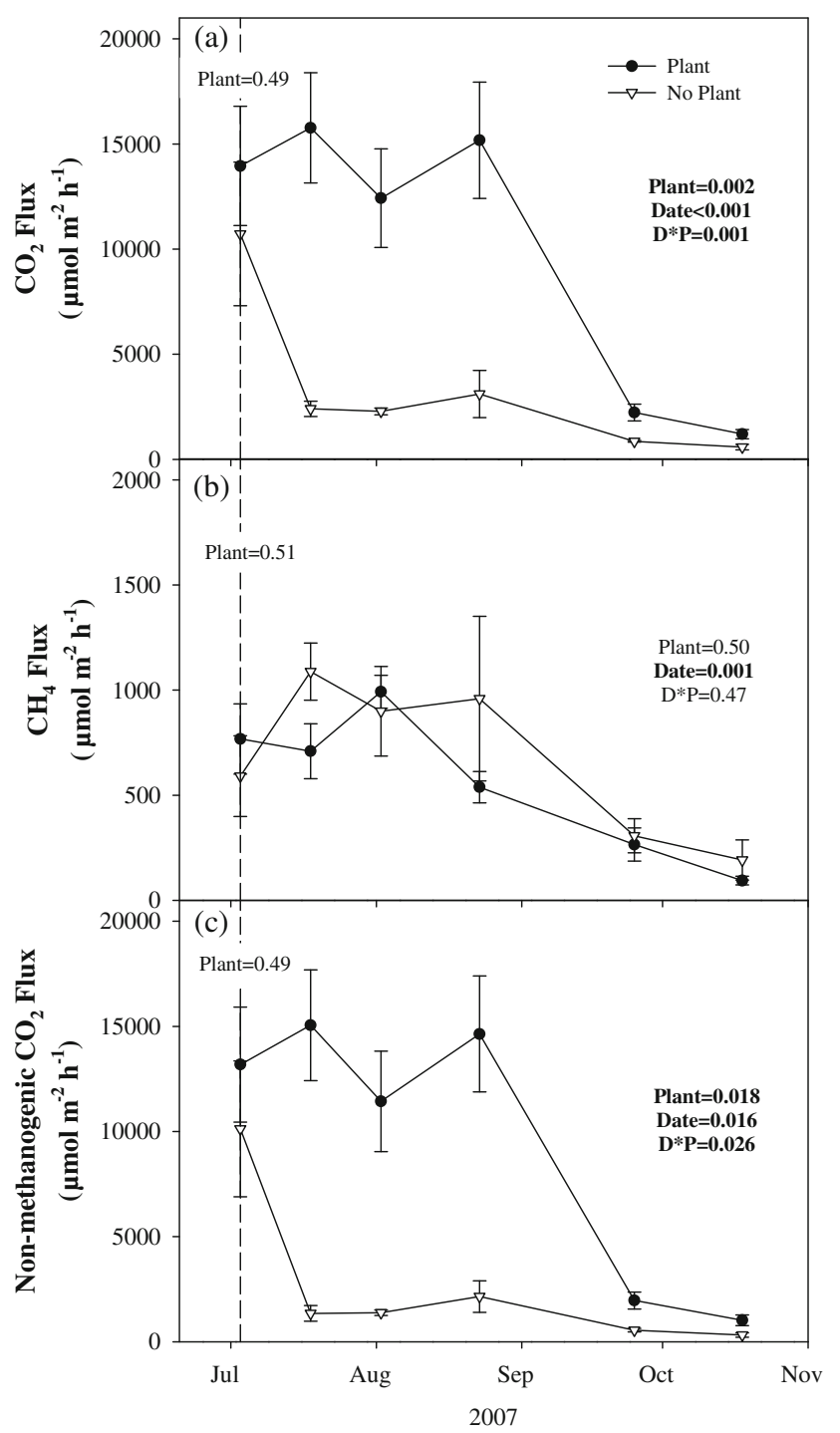

Fig. 3 Effects of plant removal on net ecosystem respiration as: $\mathrm{CO}_{2}$ (a), $\mathrm{CH}_{4}(\mathbf{b})$, and non-methanogenic $\mathrm{CO}_{2}$ (c) fluxes in a tidal freshwater wetland with an organic soil. Non-methanogenic $\mathrm{CO}_{2}$ includes $\mathrm{CO}_{2}$ produced by all non-methanogenic heterotrophic respiration as well as autotrophic respiration. This value corrects for $\mathrm{CO}_{2}$ produced by methanogenesis assuming a $\mathrm{CO}_{2}: \mathrm{CH}_{4}$ ratio of $1: 1$. Values are means $\pm 1 \mathrm{SE}$. The dashed vertical line indicates the initiation of the plant removal treatment. Results of independent sample $t$ tests used to test for plant effects prior to the initiation of the plant removal treatment are included. Results of repeated measures ANOVAs run on post-treatment data include a fixed effect of the plant treatment ("Plant"), a repeated effect ("Date") and their interaction ("D×P"). Significant effects are bolded

ingrowth cores at the Organic Site demonstrate that our plant removal treatment effectively reduced the rhizosphere volume and presumably the potential for $\mathrm{O}_{2}$ inputs into the rhizosphere. However, this treatment effect did not translate to decreased rates of iron reduction in the absence of plants. Overall, this suggests that the plant stimulation of iron reduction (and suppression of methanogenesis) observed by others (Neubauer et al. 2005; Sutton-Grier and Megonigal 2011) were not important at the ecosystem-scale in the wetlands used for this experiment. Instead, our results suggest that site conditions, including soil mineral content, and seasonal patterns likely driven by temperature (Fig. 5) were more important drivers of the outcome of the competition between methanogens and iron reducers in these tidal freshwater wetland sites.

At the Organic Site, anaerobic carbon mineralization was dominated by methanogenesis over the 2 years of this study (Fig. 4). The observed $\mathrm{CO}_{2}: \mathrm{CH}_{4}$ ratio in our laboratory incubations was close to the $1: 1$ ratio predicted for a methanogenic system (Conrad 1999), suggesting that no competing mineralization processes, including iron reduction, were releasing significant amounts of $\mathrm{CO}_{2}$. This persistent methanogenic pattern likely explains why we were unable to measure rates of $\mathrm{Fe}$ (II) accumulation in our iron reduction assays at this site. Microelectrode profiles taken near the sites used in this experiment suggested a role of manganese reduction at these sites (Ma et al. 2008), but the observed $\mathrm{CO}_{2}: \mathrm{CH}_{4}$ ratios in this experiment downplay this possibility. Interestingly, this methanogenic pattern was consistent in both the presence and absence of plants. One possibility is that any $\mathrm{Fe}$ (III) formed in the rhizosphere was immediately reduced using abundant soil organic matter as an electron donor. The apparent decline in both $\mathrm{CH}_{4}$ and $\mathrm{CO}_{2}$ production potential in the No Plant treatment (without a change in the ratio of these two gases, Fig. 4), may have been a result of declining labile organic matter availability (e.g., through root exudation) for methanogens at this site. A similar pattern was observed by Windham-Meyers et al. (2009) who showed a decrease in porewater acetate in response to plant removals in a number of saline and freshwater wetlands.

In stark contrast to the consistent methanogenic signal at the Organic Site, there was a distinct seasonal pattern in carbon mineralization pathways at the Mineral Site. As we followed pathways of carbon mineralization over a single year, we cannot generalize the seasonal patterns that we observed; but, it appears that $\mathrm{CH}_{4}$ production was suppressed by iron reduction at the start of the growing season and to a lesser extent at the end of the season (Figs. 4 and 5). Given the close proximity of the Organic and Mineral Sites used in this project ( $\sim 110 \mathrm{~m}$ apart), our divergent seasonal patterns suggest that soil type, including organic matter content and perhaps iron mineralogy, may interact with temperature variability to regulate the competition between anaerobic carbon mineralization pathways.

A similar seasonal competition between methanogens and iron reducers was observed by Neubauer et al. (2005) in a wetland at the Jug Bay Wetland Sanctuary adjacent to those used in this experiment. These authors hypothesized that methanogenesis was only able to dominate anaerobic microbial respiration following plant senescence when $\mathrm{O}_{2}$ flow to the rhizosphere had ceased and (re)oxidized iron became limiting for iron reduction (Neubauer et al. 2005). 


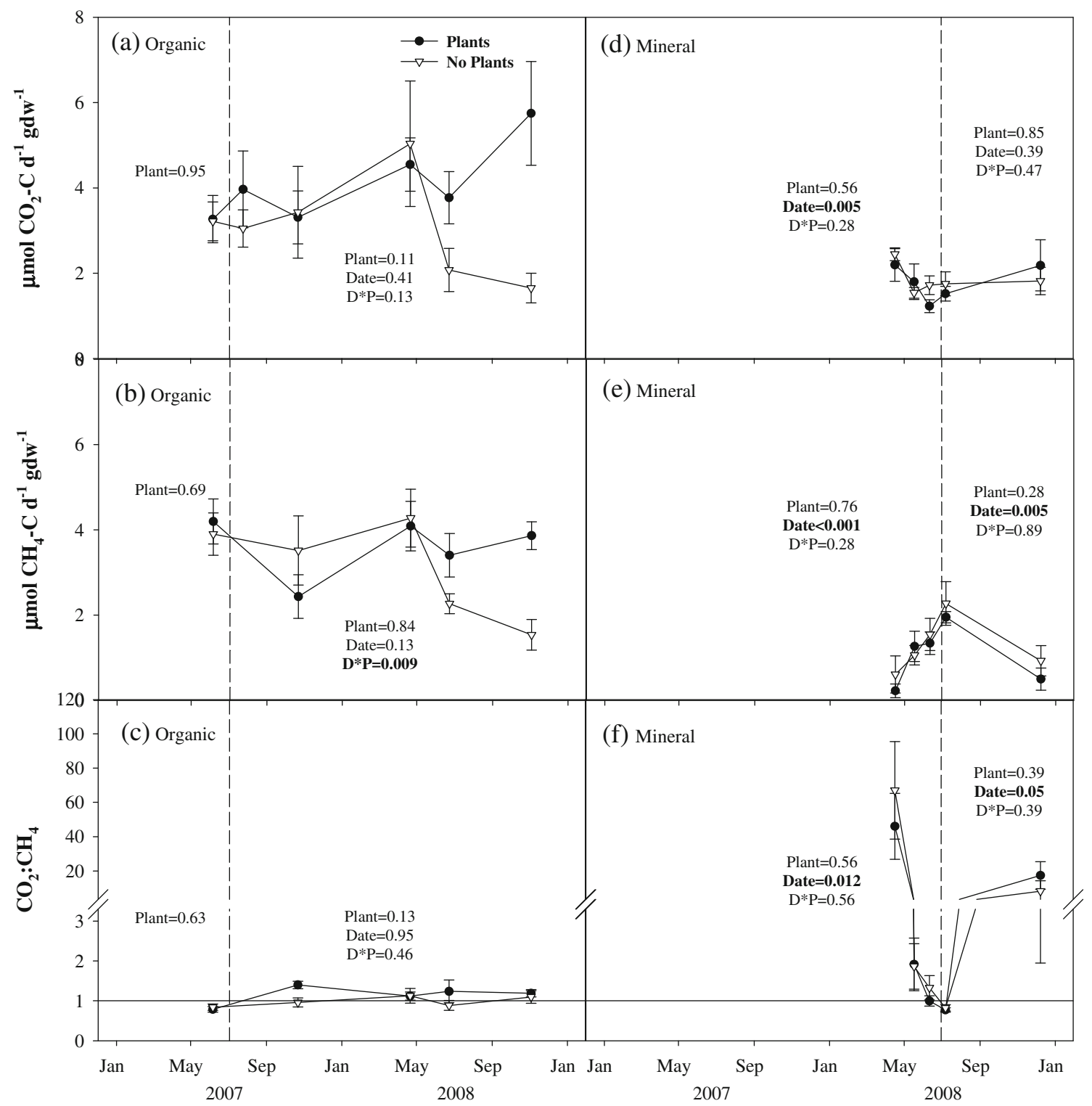

Fig. 4 Effects of plant removal on potential microbial carbon mineralization in anaerobic laboratory incubations of soils from tidal freshwater wetlands with organic $(\mathbf{a}-\mathbf{c})$ and mineral $(\mathbf{d}-\mathbf{f})$ soils. Rates of $\mathrm{CO}_{2}$ and $\mathrm{CH}_{4}$ production as well as the ratio of $\mathrm{CO}_{2}: \mathrm{CH}_{4}$ produced are included. Values are means $\pm 1 \mathrm{SE}$. The dashed vertical lines indicate the initiation of the plant removal treatment in both sites. For both sites,

At our Mineral Site, this does not seem to be the case as iron reduction declined and $\mathrm{CH}_{4}$ production increased well before plant senescence and even though all plots were still fully vegetated (Figs. 4 and 5). There is limited evidence that the removal of plants at the Mineral Site led to a decrease in rates of iron reduction by the end of our experiment (Fig. 5). Interestingly, this pattern was only present on the December sampling date, well after plants had senesced. This raises the possibility that changes in iron availability controlled by plant-mediated effects on $\mathrm{O}_{2}$ transport to the rhizosphere can persist after plant activity has ceased and results of repeated measures ANOVAs run on post-treatment data include a fixed effect of the plant treatment ("Plant"), a repeated effect ("Date") and their interaction ("D $\times \mathrm{P}$ "). At the organic site, an independent $t$ test was used to test for pre-treatment effects. At the mineral site, a repeated measures ANOVA was used. Significant effects are bolded

may take time to become apparent. For example, deposition of iron oxide in the rhizosphere could persist until environmental conditions, independent of plant activities, favored iron reduction. Plant-mediated changes in soil iron chemistry as suggested by the decreased initially extractable $\mathrm{Fe}(\mathrm{II})$ in the Plant treatment on the final sampling date at the Mineral Site (Fig. 5) may help explain these patterns.

An alternative hypothesis is that the seasonal patterns in dominant anaerobic mineralization pathways are mediated by temperature effects on iron cycling rather than by plant inputs of $\mathrm{O}_{2}$. Bullock et al. (2012) showed that iron 


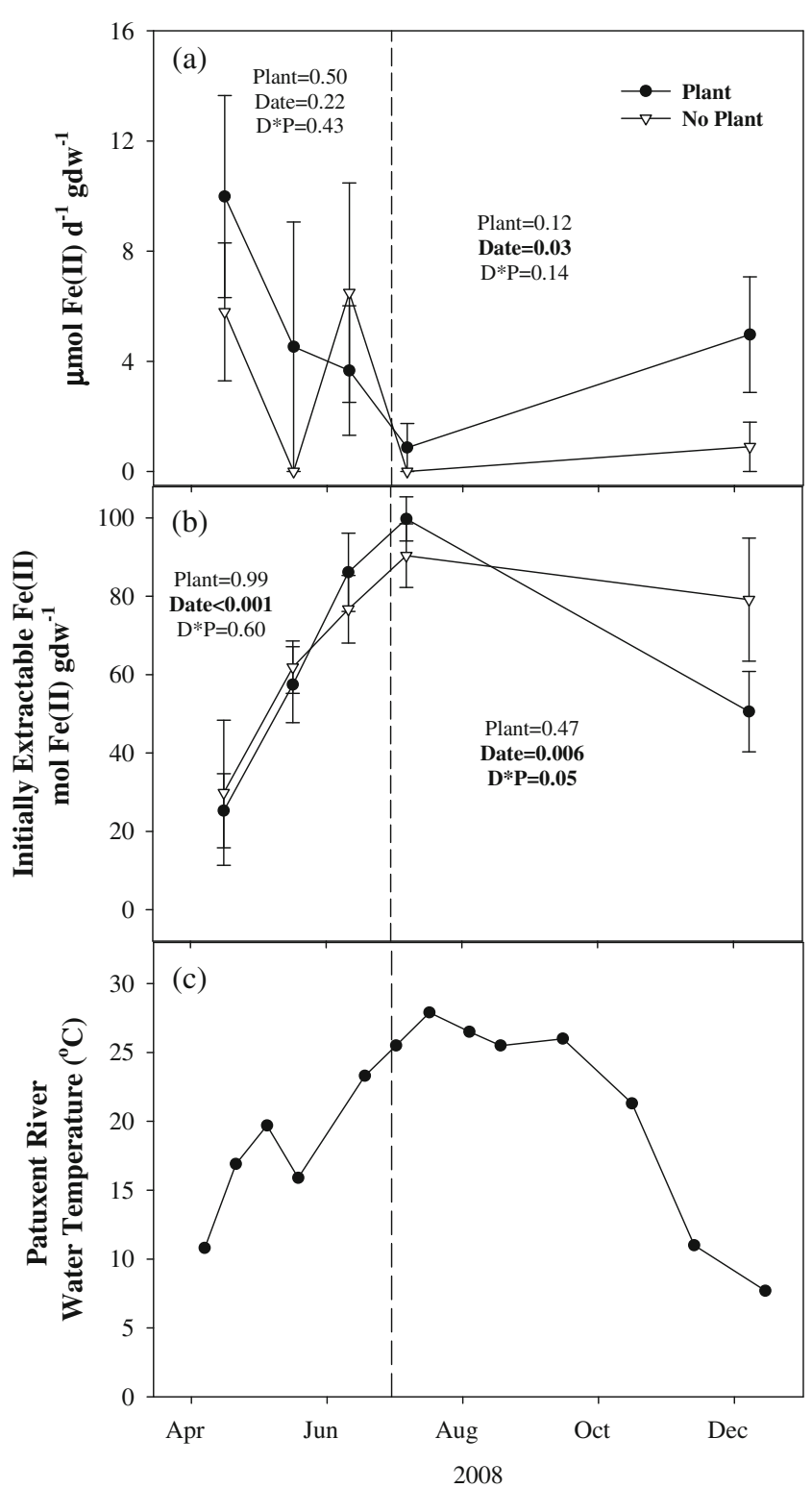

Fig. 5 Effects of plant removal on rates of $\mathrm{Fe}(\mathrm{III})$ reduction (a) in a tidal freshwater wetland with a mineral soil. Fe(III) reduction was measured as the linear accumulation of extractable Fe(II) using a weakly acidic oxalate extract. The initially extractable Fe(II) concentrations (b) are also included. Water temperatures (c) from the EPA monitoring station TF1.4 in the Patuxent River illustrate seasonal temperature patterns at this site. Statistical details follow Fig. 1

reduction is more temperature sensitive than iron oxidation in soils collected from a mud flat at the Jug Bay Wetlands Sanctuary. This pattern suggests that under colder conditions at the end of the growing season, rates of iron reduction slow faster than rates of iron oxidation allowing the oxidized iron pool to increase or at least keep pace with the demand from iron reduction. As soils warm in the spring, rates of iron reduction increase faster than rates of iron oxidation leading to a depletion of the available oxidized iron pool and a subsequent iron limitation of iron reduction.
Under these warmer soil conditions, the thermodynamically less favored process of $\mathrm{CH}_{4}$ production could become dominant as observed at the Mineral site (Fig. 4). It is also possible that differences between our results, and those of Neubauer et al. (2005) are related to the differences in the dominant vegetation (Typha-dominated at our sites versus Peltandra-dominated). These plants are known to have different rooting depths and root architecture at the Jug Bay Wetlands Sanctuary (Aat Barendregt, personal communication). Another potential explanation is the fact that the soil at the site used by Neubauer et al. (2005) had an even lower organic matter content (16\%) than our Mineral Site (30\%).

Microbial community analyses from soils in this experiment suggest that, in addition to a general lack of effects of plant removal on rates of methanogenesis, there were few impacts on the microbial communities responsible for this ecosystem process. Using tRFLP profiles of the Archaeal microbial community (based on Archaeal specific 16S rRNA analysis), as well as the methanogenic microbial community (based on mcrA sequence analysis), Emerson et al. (2012) demonstrated that these microbial communities were not strongly impacted by our plant removal treatments. This further emphasizes the apparent lack of plant-control over microbial carbon mineralization at these tidal freshwater wetland sites.

Despite few plant-mediated effects on rates of potential $\mathrm{CH}_{4}$ production, there were clear increases in porewater $\mathrm{CH}_{4}$ concentrations following plant removal in both sites (Fig. 2). Similar increases in porewater $\mathrm{CH}_{4}$ in response to plant removals in freshwater marshes have been observed previously (e.g., Ding et al. 2005; van der Nat and Middelburg 1998) and have been attributed to a number of mechanisms (Laanbroek 2010). For example Ding et al. (2005) demonstrated that increased porewater $\mathrm{CH}_{4}$ concentrations were related to a decline in aerenchymal $\mathrm{CH}_{4}$ flux through plant stems. We did not, however, observe a consistent decrease in net $\mathrm{CH}_{4}$ flux in our net ecosystem respiration measurements (Fig. 3), but we acknowledge that we may have missed a transitory decrease in $\mathrm{CH}_{4}$ "venting" through plants early in our experiment, which led to an accumulation of $\mathrm{CH}_{4}$ in porewater. It is also possible that ebullition was higher in the No Plant treatment, a process that our chambers were not designed to measure. Others have suggested that porewater $\mathrm{CH}_{4}$ accumulation following plant removal may be linked to decreased $\mathrm{CH}_{4}$ oxidation in the rhizosphere (e.g., van der Nat and Middelburg 1998; 2000). Thus, we cannot rule out the possibility that similar net fluxes between the Plant and No Plant treatments were the result of decreases in both $\mathrm{CH}_{4}$ production and $\mathrm{CH}_{4}$ oxidation. However, the $\mathrm{CO}_{2}: \mathrm{CH}_{4}$ ratio of net ecosystem respiration measured in the No Plant plots ranged from 2.4 to 3.5 in the Organic Site. This low ratio might suggest that a great deal of $\mathrm{CH}_{4}$ produced by these methanogenic soils was 
released to the atmosphere without being oxidized by methanotrophs. Alternatively, methanotrophs were effective competitors for $\mathrm{O}_{2}$ at low $\mathrm{O}_{2}$ concentrations in the rice rhizosphere (van Bodegom et al. 2001). If this process outcompeted iron oxidation, this could lead to a lack of oxidized iron accumulation in the rhizosphere and further explain the lack of measured iron reduction at this site. Finally, unforeseen influences of plant removal, including observed increases in soil temperature and likely changes in soil water content due to changes in transpiration and advective porewater turnover could have influenced porewater chemistry and microbial processes.

Our objective was to understand the plant-mediated processes that regulate microbial competition for electron acceptors and ultimately methane emissions. Over the course of the 2007 growing season following the initiation of the plant removal treatments (17 July-18 October), total $\mathrm{CH}_{4}$ emissions were $18 \mathrm{~g} \mathrm{CH}_{4} \mathrm{~m}^{-2}$ and $24 \mathrm{~g} \mathrm{CH}_{4} \mathrm{~m}^{-2}$ from the Plant and No Plant treatments, respectively. These values are well within the range of annual $\mathrm{CH}_{4}$ flux from other North American freshwater wetlands, falling above the median and below the mean reported by (Poffenbarger et al. 2011) and represent $5 \%$ and $26 \%$ of the net seasonal ecosystem respiration $\left(\mathrm{CO}_{2}+\mathrm{CH}_{4}\right.$ flux $)$ in the Plant and No Plant treatment, respectively. Poffenbarger et al. (2011) reported that methane emissions from tidal freshwater wetlands are highly variable and suggested that these systems can function as either net sinks or net sources of greenhouse gases with respect to radiative forcing. Our data indicate that spatial and temporal variation in competition between iron reducers and methanogenesis may be one cause of the variation in methane emissions. While iron cycling appears to competitively suppress $\mathrm{CH}_{4}$ production early and late in the growing season at the Mineral Site, these seasonal patterns are not present at the Organic Site suggesting that differences in site condition, including soil organic matter content, may mediate this microbial competition.

Our experimental design allows for a unique exploration of the relative contribution of heterotrophic vs. autotrophic respiration at the Organic Site. Given that microbial carbon mineralization appears to be methanogenic $\left(\mathrm{CO}_{2}: \mathrm{CH}_{4}=1: 1\right)$ throughout the study period at this site (Fig. 4), we were able to remove methanogenic $\mathrm{CO}_{2}$ from the net flux of $\mathrm{CO}_{2}$ measured in these chambers. The remaining nonmethanogenic $\mathrm{CO}_{2}$ flux represents the sum of all other heterotrophic processes $\left(\mathrm{CH}_{4}\right.$ oxidation, aerobic respiration in surface soils, etc.) and autotrophic respiration from above- and belowground plant and algal biomass. To the extent that our plant removal treatments effectively removed plants, the difference in the non-methanogenic $\mathrm{CO}_{2}$ fluxes between the Plant and No Plant treatments approximates autotrophic respiration. Using this approach as a first approximation suggests that plant respiration was responsible for $91 \%$ of the total non-methanogenic $\mathrm{CO}_{2}$ flux in the Plant plots in July and declined through the season to a value of $69 \%$ in October following senescence of the aboveground biomass (Fig. 3). There are clearly limitations to this approach. For example, our inability to capture $\mathrm{CH}_{4}$ ebullition using flux chambers may have underestimated the true contribution of heterotrophic processes at this site. Furthermore, NER data only exist for six sampling dates at the Organic Site. While extrapolations of our results to larger spatial or temporal scales are likely to be problematic, as a first approximation, our results suggest that autotrophic respiration likely dominates net ecosystem $\mathrm{CO}_{2}$ flux in this system.

\section{Summary}

In contrast to our initial hypothesis, there was little evidence that the presence of plants facilitated iron reduction or competitively suppressed $\mathrm{CH}_{4}$ production due to increased iron oxide availability resulting from a relatively large oxidized rhizosphere volume. At the Organic site, methanogenesis was the dominant anaerobic carbon mineralization process throughout the growing season despite the presence of dissolved $\mathrm{Fe}$ (II) and an active plant community. At the Mineral site, there were clear seasonal shifts in the relative importance of iron reduction and methanogenesis, with iron reduction playing a larger role in anaerobic carbon metabolism both early and late in the season (when soil temperatures were lower), regardless of the presence or absence of plants.

These patterns show that the controls of iron reduction and methanogenesis, and the competitive outcome of these two processes, in tidal freshwater wetlands are complex and multifaceted. Plant-microbe interactions leading to increased rates of iron oxidation and reduction in an oxidized rhizosphere are possible (e.g., Neubauer et al. 2005; Roden and Wetzel 1996), but appear not to be universal (e.g., our study). The competition between iron reduction and methanogenesis is also clearly related to site conditions, and may vary with soil organic matter content, given that anaerobic metabolism differed dramatically between our Organic and Mineral site despite close spatial proximity. Soil organic matter may play a role in this competition either directly (as an electron donor for mineralization) or indirectly (through effects on soil iron chemistry). Finally, even within a soil type (i.e., the Mineral Site), there can be distinct seasonal patterns in anaerobic carbon mineralization with methanogenesis dominating carbon cycling even in the presence of an active plant community that may be related to different temperature responses of microbial processes such as iron reduction and iron oxidation. Thus, iron and $\mathrm{CH}_{4}$ cycling are likely to vary dramatically among tidal freshwater wetlands making generalizations about $\mathrm{CH}_{4}$ flux and soil carbon storage in these ecosystems in the context of ongoing global change particularly challenging. 
Acknowledgments Chris Swarth at the Jug Bay Wetlands Sanctuary allowed unfettered access to our research sites for this project. We thank Jim Duls, Nick Mudd, Lucinda Williams, Pamela Weisenhorn, Sara McQueeney, Kyle Chambers, and Eric Pfoutz for assistance with field and laboratory work on this project. Comments from two anonymous reviewers greatly improved this manuscript. This research was supported by NSF DEB-0516400 to JPM and Smithsonian PostDoctoral Fellowships to JKK and AES-G.

\section{References}

Bartlett, K.B., D.S. Bartlett, R.C. Harriss, and D.I. Sebacher. 1987. Methane emissions along a salt marsh salinity gradient. Biogeochemistry 4: 183-202.

Bridgham, S.D., J.P. Megonigal, J.K. Keller, N.B. Bliss, and C. Trettin. 2006. The carbon balance of North American wetlands. Wetlands 26: 889-916.

Bullock A., A.E. Sutton-Grier, and J.P. Megonigal 2012. Anaerobic metabolism in tidal freswhater wetlands: II. Temperature sensitivy of microbial iron cycling. Estuaries and Coasts. doi:10.1007/ s12237-012-9536-5.

Conrad, R. 1999. Contribution of hydrogen to methane production and control of hydrogen concentrations in methanogenic soils and sediments. FEMS Microbiology Ecology 28: 193-202.

Denman K.L., et al. 2007. Couplings Between Changes in the Climate System and Biogeochemistry. In Climate Change 2007: The Physical Science Basis. Contribution of Working Group I to the Fourth Assessment Report of the Intergovernmental Panel on Climate Change eds Solomon S, D. Qin, M. Manning, Z. Chen, M. Marquis, K.B. Averyt, M.Tignor and H.L. Miller, Cambridge, United Kingdom and New York, NY, USA: Cambridge University Press.

Ding, W., Z. Cai, and H. Tsuruta. 2005. Plant species effects on methane emissions from freshwater marshes. Atmospheric Environment 39: 3199-3027.

Eaton A.D., L.S. Clesceri, and A.E. Greenberg. 1995. Standard methods for the examination of water and wastewater. Washington, DC: American Public Health Association.

Emerson D., W. Bellows, J.K. Keller, A.E. Sutton-Grier, and J.P. Megonigal. 2012. Anaerobic metabolism in tidal freswhater wetlands: III. Effects of plant removal on Archaeal microbial communities. Estuaries and Coasts. doi:10.1007/s12237-012-9496-9.

Forster, P., V. Ramaswamy, P. Artaxo, T. Berntsen, R. Betts, D.W. Fahey, J. Haywood, J. Lean, D.C. Lowe, G. Myhre, J. Nganga, R. Prinn, G. Raga, M. Schulz, and R. Van Dorland. 2007. Changes in atmospheric constituents and in radiative forcing. In Climate change 2007: The physical science basis. Contribution of working group I to the fourth assessment report of the intergovernmental panel on climate change, eds. Solomon, S., D. Qin, M. Manning, Z. Chen, M. Marquis, K.B. Averyt, M. Tignor and H.L. Miller, Cambridge, United Kingdom and New York, NY, USA: Cambridge University Press.

Giblin, A.E., and R.W. Howarth. 1984. Porewater evidence for a dynamic sedimentary iron cycle in salt marshes. Limnology and Oceanography 29: 47-63.

Keller, J.K., A.A. Wolf, P.B. Weisenhorn, B.G. Drake, and J.P. Megonigal. 2009. Elevated $\mathrm{CO}_{2}$ affects porewater chemistry in a brackish marsh. Biogeochemistry 96: 101-117.

Kelley, C.A., C.S. Martens, and J.P. Chanton. 1990. Variations in sedimentary carbon remineralization rates in the White Oak River esturary, North Carolina. Limnology and Oceanography 35: 372-383.

Kostka, J.E., and G.W. Luther. 1995. Seasonal cycling of Fe in saltmarsh sediments. Biogeochemistry 29: 159-181.
Laanbroek, H.J. 2010. Methane emission from natural wetlands: interplay between emergent macrophytes and soil microbial processes. A mini-review. Annals of Botany 105: 141-153.

Lovley, D.R., and E.J.P. Phillips. 1986a. Organic matter mineralization with reduction of ferric iron in anaerobic sediments. Applied and Environmental Microbiology 51: 683-689.

Lovley, D.R., and E.J.P. Phillips. 1986b. Availability of ferric iron for microbial reduction in bottom sediments of the freshwater tidal Potomac River. Applied and Environmental Microbiology 52: 751-757.

Ma, S., G.W. Luther, J. Keller, A.S. Madison, E. Metzger, J.P. Megonigal, and D. Emerson. 2008. Solid-state $\mathrm{Au} / \mathrm{Hg}$ microelectrodes for the investigation of $\mathrm{Fe}$ and $\mathrm{Mn}$ cycling in a freshwater wetland: implications for methane production. Electranalysis 20: $233-293$

Marsh A.S., D.P. Rasse, B.G. Drake, and J.P. Megonigal. 2005. Effect of elevated $\mathrm{CO}_{2}$ on carbon pools and fluxes in a brackish marsh. Estuaries 28: 694-704.

Megonigal J.P., and S.C. Neubauer. 2009. Biogeochemistry of tidal freshwater wetlands. In Coastal wetlands: an integrated ecosystem approach, eds Perillo G, Wolanski E, Cahoon D, Brinson M, Elsevier.

Megonigal, J.P., M.E. Hines, and P.T. Visscher. 2004. Anaerobic metabolism: linkages to trace gases and aerobic processes. In Biogeochemistry, ed. W.H. Schlesinger, 317-424. Oxford: Elsevier-Pergamon.

Neubauer, S.C., D. Emerson, and J.P. Megonigal. 2002. Life at the energetic edge: kinetics of circumneutral iron oxidation by lithotrophic iron-oxidizing bacteria isolated from the wetland-plant rhizosphere. Applied and Environmental Microbiology 68: 3988-3995.

Neubauer, S.C., K. Givler, S.K. Valentine, and J.P. Megonigal. 2005. Seasonal patterns and plant-mediated controls of subsurface wetland biogeochemistry. Ecology 86: 3334-3344.

Phillips, E.J.P., and D.R. Lovley. 1987. Determination of Fe(III) and Fe (II) in oxalate extracts of sediment. Soil Science Society of America Journal 51: 938-941.

Poffenbarger, H.J., B.A. Needelman, and J.P. Megonigal. 2011. Salinity influence on methane emissions from tidal marshes. Wetlands 31: 831-842.

Roden, E.E. 2003. Diversion of electron flow from methanogenesis to crystalline $\mathrm{Fe}(\mathrm{III})$ oxide reduction in carbon-limited cultrues of wetalnd sediment mciroorganisms. Applied and Environmental Microbiology 69: 5702-5706.

Roden, E.E., and R.G. Wetzel. 1996. Organic carbon oxidation and suppression of methane production by microbial Fe(III) oxide reduction in vegetated and unvegetated freshwater sediments. Limnology and Oceanography 41: 1733-1748.

Roden, E.E., and R.G. Wetzel. 2002. Kinetics of microbial Fe(III) oxide reduction in freshwater wetland sediments. Limnology and Oceanography 47: 198-211.

Roden, E.E., and R.G. Wetzel. 2003. Competition between Fe(III)reducing and methanogenic bacteria for acetate in iron-rich freshwater sediments. Microbial Ecology 45: 252-258.

Sutton-Grier, A.E., and J.P. Megonigal. 2011. Plant species traits regulate methane production in freshwater wetland soils. Soil Biology and Biochemistry 43: 413-420.

Taylor, G.J., A.A. Crowder, and R. Rodden. 1984. Formation and morphology of an iron plaque on the roots of Typha latifolia L. grown in solution culture. American Journal of Botany 71: 666-675.

van Bodegom, P., J. Goudriaan, and P. Leffelaar. 2001. A mechanistic model on methane oxidation in a rice rhizosphere. Biogeochemistry 55: 145-177.

van der Nat, F.-J., and J.J. Middelburg. 1998. Effects of two common macrophytes on methane dynamics in freshwater sediments. Biogeochemistry 43: 79-104. 
van der Nat, F.J., and J.J. Middelburg. 2000. Methane emission from tidal freshwater marshes. Biogeochemistry 49: 103-121.

Weiss, J.V., D. Emerson, and J.P. Megonigal. 2004. Geochemical control of microbial Fe(III) reduction potential in wetlands: comparison of the rhizosphere and non-rhizosphere soil. FEMS Microbiology Ecology 48: 89-100.

Whigham D.F. 2009. Primary production in tidal freshwater wetlands. In Tidal Freshwater Wetlands, eds Barendregt A, Whigham D,
Baldwin A, 115-122. Backhuys Publishers, Leiden; Margraf Publishers, Weikersheim.

Windham-Myers L., M. Marvin-Dipasquale, D.P. Krabbenhoft, J.L. Agee, M.H. Cox, P. Heredia-Middleton, C. Coates, and E. Kakouros. 2009. Experimental removal of wetland emergent vegetation leads to decreased methylmercury production in surface sediments. Journal of Geophysical Research 114: G00C05. 